in particular as they affect young people, the College set up a working party in 1962 to consider problems of accident prevention and life saving. It culminated in the holding of a public convention in May $1963 . .^{4}$ The two main conclusions of the report are, first, that so far as the prevention of accidents is concerned "the behaviour of the individual is the dominant feature," and, secondly, so far as life saving is concerned all the technical aspects have " considerable medical significance."

In Great Britain accidental deaths now number about 20,000 a year, of which about 7,000 occur on the roads and 8,000 in homes. About 1,000 persons are killed annually at work, $600-700$ of them in industry. As many as 300,000 patients are admitted to hospital annually because of accidental injury. It is thus an enormous problem, and a notable feature of it is that young people under the age of 25 are specially vulnerable to accidental injury. But while these statistics give some idea of the size of the problem they hide its complexity. That many interrelated factors play their part in causing road accidents is well known. Research into them is in its early stages. Perhaps even less advanced is research into the great variety of accidents in the home. The explorations of young toddlers and the fumblings of elderly totterers clearly underlie many accidents. But the report questions whether parents give their children enough training to meet the hazards of a home equipped with all sorts of appliances driven or heated by electricity and gas. It may be that parents who fail in this respect are themselves on the average more prone to accidents than others-" Observation over a period of $11 \frac{1}{2}$ years shows that $1.74 \%$ of the number at risk account for $53.79 \%$ of all accidents and that the accident-prone person is also sick-prone." A type of accident of special concern to medical men has recently been reported on by L. L. Griffiths. ${ }^{6}$ He examined causes of accidents in nine hospitals of various types and found that high beds were prominent as a source of trouble.

The working party considers that doctors should take a bigger interest in these matters and suggests that a fundamental approach is required, one which goes back to the origins of behaviour and mental attitudes. Consequently it expresses the hope that the College will set up a permanent independent commission of medical men representing expert opinion in the fields of accident prevention, first aid, and life saving. This body could then provide guidance for Government departments, voluntary societies, and other organizations concerned with these matters. It also makes the suggestion that the commission should study the needs for and initiate research (though presumably not direct it), if necessary enlisting the assistance of scientists in other fields. Naturally such a commission would be powerless without funds, and one suggestion put forward is that the life assurance companies might be approached for financial support, since any improvements in accident rates which might come about as a result of its activities would be directly to their advantage.

The working party stresses the need for doctors to use their influence to educate people in the prevention of accidents, and it urges them to take a larger part in all aspects of first-aid development and training. Medical students should receive instruction of the highest standard in first aid. These suggestions must surely commend themselves to most medical

\footnotetext{
1 Brit. med. f., 1964, 1, 69.

2 Gissane, W., and Bull, J., ibid., 1964, 1, 75.

Working Party on Accident Prevention and Life Saving 1961-1963, 1963. Royal College of Surgeons of England.

4 Brit. med. ₹., 1963, 1, 1362.

Ibid., 1963, 1, 1404.

- Griffiths, L. L., Mth. Bull. Minist. Hlth Lab. Serv., 1963, 22, 22.
}

men. There is much to be said for having a standing commission on the lines suggested, for it could play an important part in dispelling the laissez-faire attitude which is too prevalent at present.

\section{Hidden Reserves}

A good layer of fat has always been thought of as a standby against hunger and cold, and in spite of our localized prosperity we still need protection against these two enemies. ${ }^{1}$ As a food reserve in mammals, including man, carbohydrate has never been regarded as having the same importance, though the role of glycogen in the liver in stabilizing the blood sugar has been known since the time of Claude Bernard, while the glycogen stored in muscles is essential for muscular activity, particularly in states of hypoxia or " oxygen debt." Only a few animals have been favoured with any material reserves of fat in their bodies at birth, but fortunately for us the human infant is one of them. Yet all newborn animals can survive a surprisingly long time after birth even if they are not suckled, and similarly the human infant can live without risk for a period of several days. ${ }^{2}$

It was difficult for a long time to understand where the energy requirements for these periods of starvation come from, and the resistance of the newborn animal to hypoxia and cold has also been puzzling. What were the hidden reserves ? It has gradually come to light that they must in fact be carbohydrates and that there may not always be enough of them. Thus newborn pigs, which will live happily for thirtysix hours or more in a comfortably warm environment, die of hypoglycaemia within twenty-four hours of birth if their metabolism is maintained continuously at a high level by cold surroundings. ${ }^{3-5}$ The extensive and valuable nature of these reserves has gradually been revealed over the last few years by a group working at Oxford. ${ }^{6}$

The concentration of glycogen in the liver rises in all species from about half to three-quarters of the way through gestation to a peak at birth and falls rapidly in the next day or two, only to rise again more slowly towards the adult level. The level of glycogen in the heart is also high at birth by adult standards and was higher still in gestation. Its concentration at birth varies with the species and the maturity of the species at this time. The glycogen in the muscles rises in the same way as it does in the liver, and in the sheep may reach figures

\footnotetext{
'Brit. med. F., 1964, 1, 4. Somatic Stability in the Newly Born, Ciba Foundation Symposium, 1961, ed. G. E. W. Wolstenholme and M. O'Connor. London.

3 Morrilh, C. C., Amer. F. vet. Res., 1952, 13, 322.

and Sampson, J., ibid., 1952, 13, 327.

Goodwin, R. F. W., f. Physiol. (Lond.), 1957, 136, 208.

6 Shelley, H. J., Brit. med. Bull., 1961, 17, 137.

Dawes, G. S., Mott, J. C., Shelley, H. J., and Stafford, A., F. Physiol. (Lond.), 1963, 168, 43.

- Usher, R. in Somatic Stability in the Newly Born, Ciba Foundation Symposium, 1961, ed. G. E. W. Wolstenholme and M. O'Connor. London.

9 Brit. med. f., 1964, 1, 70.

10 McCance, R. A., and Widdowson, E. M., F. Physiol. (Lond.), 1959,

1 147, 124. Blaxter, K. L., in Milk: The Mammary Gland and its Secretion, 1961, ed. S. K. Kon and A. T. Cowie. London.

12 Parsons, D. S., and Rossum, G. D. V. Van, Nature (Lond.), 1963, 200, 268.

13 Mann, T. P and Elliott, R. I. K Lancet, 1957, 1, 229.

14 Bower, B. D., Jones, L. F., and Weeks, M. M., Brit. med. F., 1960, 1, 303 .

15 Neligan, G. A., Robson, E., and Watson, J., Lancet, 1963, 1, 1282

16 Brown, R. J. K., and Wallis, P. G., ibid., 1963, 1, 1278. Smith, C., The Physiology of the Newborn Infant, 1959, p. 211.
Springfield, Ill.
} 
of $40-75 \mathrm{mg} . / \mathrm{g}$. of wet weight. These reserves all have a special function and value to the newborn animal. G. S. Dawes and his colleagues, ${ }^{7}$ for example, have shown by years of patient work that the survival time of an asphyxiated newborn animal probably depends on the amount of glycogen available in the heart, and they have shown that the time can be raised by infusions of glucose to supplement the glycogen and of sodium carbonate to counteract the fall in $p H$ due to anaerobic breakdown of the glycogen to lactic acid. Their work is interesting experimental justification for the use of glucose and bicarbonate infusions in the treatment of infantile respiratory distress, ${ }^{8}$ some aspects of which were discussed recently in these columns. ${ }^{9}$ The glycogen in the skeletal muscles is part of the newborn animal's protection against cold, and it disappears much more rapidly in chilled newborn animals than in those kept in warm surroundings. ${ }^{10}$ The glycogen in the liver is a more general reserve and is broken down to supply glucose to the plasma to be used by any of the tissues which are in need of it. The newborn animal may possibly draw upon it to supplement the lactose in its mother's milk, which in some species-and among them the rat -contains very little. ${ }^{11}$ The extent to which the liver may store glycogen has been shown by D. S. Parsons and G. D. V. Van Rossum, ${ }^{12}$ who calculated that in the rat liver the glycogen rose from nothing to more than $40 \%$ of the total dry solids during the last four days of gestation and fell again to $5 \%$ in the next 24 hours. The interest of this work would be enhanced by taking into account the weights of all the organs involved and then calculating the total amounts of glycogen broken down during these critical hours just after birth.

In the present issue of the B.M.F. H. J. Shelley publishes a paper on the carbohydrate reserves of the newborn baby (page 273). The work must have had its disappointments, for a survey of the cases shows how impossible it has been to obtain material to analyse from an entirely normal newborn baby. There is, however, no doubt at all that the human baby falls into line with other newborn mammals in having considerable reserves of glycogen in its liver, muscles, and heart, and they must make a material difference to its chances of survival. These reserves are sometimes not enough, for it is well known now that hypoglycaemia, sometimes accentuated by cold, ${ }^{13}$ is one of the dangers threatening the newborn infant ${ }^{14-16}$ particularly one that has been undernourished during the latter part of gestation. A problem for the future is to find out more about how the reserves of fat in the human infant are related functionally with the reserves of carbohydrate. ${ }^{17}$

\section{Epidemic Keratoconjunctivitis}

In 1889 two Austrian ophthalmologists described an unusual form of acute conjunctivitis-superficial keratitis with subepithelial corneal opacities. The condition was termed nummular keratitis, superficial punctate keratitis, and by a variety of other names. ${ }^{2}$ During the next 40 years the disease was recognized in sporadic and epidemic form in many parts of the world, but did not attract much attention until the second world war. In the summer of 1941 an epidemic developed in the naval shipyards of Pearl Harbour and San Francisco and spread to many towns in California. Several thousand people, including many workers in the shipyards, were affected. M. J. Hogan and J. W. Crawford ${ }^{3}$ in a detailed description of these cases chose the term " epidemic keratoconjunctivitis" (E.K.C.). Further outbreaks were reported in many parts of North America in the following year and again in 1947-8. It was noticed at the time that the disease appeared to be limited to two groups-first, workers in shipyards (hence the term "shipyard eye") and the heavy metal industry ; secondly, ophthalmologists, staff, and patients attending eye hospitals and clinics. Few cases were reported in contacts or in the general population.

That a virus was the cause of E.K.C. had long been suspected on indirect evidence in that the disease was clearly infectious, no bacterial pathogen could be isolated, and the inflammatory response was predominantly mononuclear. In 1955 E. Jawetz and his colleagues ${ }^{4}$ isolated an adenovirus type 8 from conjunctival scrapings. Type 8 is the only serological type of adenovirus that has consistently been isolated from cases of E.K.C., whereas other types have been recovered from cases of acute follicular conjunctivitis without corneal involvement.

Virological studies have helped to unravel some of the mysteries of the epidemiology of this disease. ${ }^{5}$ In Western countries subclinical infection is rare; for example, in the U.S.A. only $5 \%$ of the adults have antibody to this particular strain of adenovirus. Thus in the West the majority of adults are susceptible to the type 8 strain. Clinical infection is limited to the eye, which seems to be the portal of entry and the main target organ. In the East subclinical infection is common. Serological studies have shown that $30 \%$ of adults in Japan have antibody and $60 \%$ in Taiwan. In Japan E.K.C. is not an occupational disease but a common childhood infection which is often accompanied by a systemic illness with fever, respiratory symptoms, and a pseudomembranous conjunctivitis. It has also been shown that very small amounts of infectious virus are produced either in the infected eye or experimentally in cell cultures. ${ }^{6}$ These factors account for the way in which infection spreads in eye clinics by direct transfer of virus from patient to patient as a result of manipulation of the patient's eyelids, and also for the lack of spread among contacts.

Two outbreaks recently reported emphasize these points. ${ }^{78}$ An outbreak of E.K.C. developed in schoolchildren in a desert community in California during a seasonal outbreak of " pink eye." A few cases also occurred in family contacts, crossinfection probably being facilitated by the copious exudate from secondary bacterial infection. ${ }^{7}$ At the same time an outbreak occurred among patients attending the physician looking after this community. Twenty-seven patients and the physician were diagnosed by the typical history, presence of subepithelial corneal opacities, and antibody to type 8 virus. The initial cases occurred in children from the local school ; the physician became infected, and then a succession of patients in a cycle of cross-infection. It was of significance that none of the children attending for ear-nose-and-throat examination became infected, whereas the attack-rate in those attending for eye complaints was $21 \%$. Of the various ophthalmic procedures to which the patient was subjected, tonometry and instillation of therapeutic drops carried the

\footnotetext{
1 Von Sttelwag, K., Wien. klin. Wschr., 1889, 2, 613

2 Fuchs, E., ibid., 1889, $2,837$.

s Hogan, M. J., and Crawford, J. W., Amer. F. Ophthal., 1942, 25, 1059

- Jawetz, E., Kimura, S., Nicholas, A. N., Thygeson, P., and Hanna, L., Science, 1955, 122,1190

- Jawetz, E., Brit. med. F., 1959, 1, 873.

27 Hanna, L., Nicholas, A., and Hoyt, R., Amer. f. Hyg., 1958, 67, 276.

7 Dawson, C., and Darrell, R., New Engl. F. Med., 1963, 268, 1031.
} 